\title{
Endophytic colonization by Beauveria bassiana increases the resistance of tomatoes against Bemisia tabaci
}

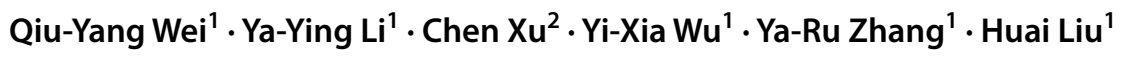

Received: 11 November 2019 / Accepted: 15 February 2020 / Published online: 4 March 2020

(c) The Author(s) 2020

\begin{abstract}
Beauveria bassiana, an entomopathogenic fungus, can exist asymptomatically as an endophyte in many plants. This study aimed to determine the efficiency of $B$. bassiana colonization of tomato plants using different inoculation methods, and how colonization of the host plant affects the key pest of tomato, the whitefly Bemisia tabaci. To confirm fungal colonization efficiency, nested PCR technique was used to detect B. bassiana sequences in Solanum lycopersicum. Distribution of the fungus within the plant parts was determined by selective medium. Tomato growth parameters were determined with plants that had been inoculated using direct spraying or irrigation of the rhizosphere. B. tabaci performance assays were carried out in a cage, and preference to treatments was determined using Y-tube olfactometer studies. Results show that B. bassiana can effectively colonize tomato, with colonization rate using leaf spraying reaching $100 \%$ within 14 days. Fungal presence was not uniformly distributed among plant parts, but was biased towards the inoculation sites. For inoculation, conidial suspension sprayed at $1 \times 10^{8}$ conidia/ml resulted in the highest number of isolated colonies in leaf tissue, $8.5 \pm 2.02$ colonies per $2 \mathrm{~g}$ of fresh tissue $\left(F_{4,19}=2.779, P=0.045\right)$, and reached the lowest with root treatment. Although only small differences were observed among the growth indicators, leaf spray inoculation resulted in a significant positive influence on plant growth (PC1 55.7\% contributions scores = 2.645) in further Principal component analysis. As for the feeding selectivity, B. tabaci preferred uninoculated plants. In Y-tube olfactometer assay, $80.5 \%$ of adults selected uninoculated plants. These findings add to the understanding of the interactions between B. bassiana and plants and indicate the potential of expanding the use of entomopathogenic fungi for crop protection.
\end{abstract}

Keywords Nested PCR $\cdot$ Inoculation method $\cdot$ Whitefly feeding preference $\cdot$ Induced resistance

\section{Introduction}

Beauveria bassiana (Ascomycota: Hypocreales) is an entomogenous fungus with an extremely broad host spectrum. Products based on B. bassiana are marketed for agricultural pest management, being often a viable alternative for the control of insect pests, including those with sucking

Communicated by Ingeborg Menzler-Hokkanen.

Qiu-Yang Wei and Ya-Ying Li contributed equally to this work.

Huai Liu

liuhuai@swu.edu.cn

1 Key Laboratory of Entomology and Pest Control Engineering, College of Plant Protection, Southwest University, Chongqing 400716, China

2 Chongqing Tobacco Science Research Institute, Chongqing 400715, China mouthparts (Shikano 2017). However, fungal spores are susceptible during germination to natural abiotic factors such as temperature, humidity, and ultraviolet radiation, which reduce the control efficacy (Zhang et al. 2009).

Previous research has revealed that a variety of entomogenous fungi can colonize plants, causing high mortality among pests feeding on the plants (Vega 2008). This observation greatly broadened the horizons for the interactions between entomogenous fungi and plants. Some results suggest that conidia not only attach to the plant surface, but can also enter the plant (Posada et al. 2007). These fungi can colonize various plant tissues for several months, and can affect the physiological activities of plants, although the colonized tissues and the length of persistence varies with the system (Brownbridge et al. 2012; Shikano 2017).

It is noteworthy that entomogenous fungi inside the plant tissues can exchange carbon and nitrogen and have been shown to promote plant growth (Pineda et al. 2010). 
Similar findings demonstrate the presence of widespread extra radical mycelium networks of entomogenous fungi, which may act as a transmission channel to help plants to acquire nutrients and water (Song et al. 2015). Therefore, some entomogenous fungi are likely to exhibit doublepositive effects in agricultural management systems. At the same time, entomopathogenic fungi can induce systemic resistance in plants, and function as beneficial biocontrol microbes against insects (Vega 2018).

Colonization by microbes that induce systemic resistance, provokes a specific physiological state in plants called "priming" (Aime et al. 2013). The primed plants show quicker and/or stronger induction of various cellular defense responses than untreated plants, after exposure to pathogens, herbivorous insects, or abiotic stress (Hokkanen and Menzler-Hokkanen 2017; Kuc 1987; Martinez-Medina et al. 2016; Slaughter et al. 2012; Ye et al. 2013). Many well-known defense systems have evolved to combat insect attack (Akello and Sikora 2012; Allegrucci et al. 2018). This process mainly involves antifeedant or toxic compounds that inhibit insect performance (McCormick et al. 2016), even emission of volatiles that attract natural enemies (Shivaramu et al. 2017). Especially the induced volatile organic compounds (VOCs) after fungal colonization (Sun et al. 2016) are crucially important. VOCs represent a complex informative signal (Jaenike 1990) and play a vital role in host discovery of herbivorous insects (Pagadala et al. 2014).

In addition to being directly applied as a biocontrol agent as a foliar spray or via soil application, B. bassiana also has been shown to reduce herbivory following their colonization of plants as endophytes (Jaber and Ownley 2018). Plant colonization by $B$. bassiana has been reported to reduce damage caused by the banana weevil, Cosmopolites sordidus (Coleoptera: Curculionidae) in banana (Akello et al. 2008); the poppy stem gall wasp, Iraella luteipes (Hymenoptera: Cynipidae) in opium poppy (Quesada-Moraga et al. 2009), and Sesamia calamistis (Lepidoptera: Noctuidae) in maize (Cherry et al. 2004). This is most likely due to plant systemic resistance, elicited by these fungi against insect herbivores (Ownley et al. 2008). Induced systemic resistance (ISR) is an important mechanism by which the whole plant is primed for enhanced defense against a broad range of insect pests (Pieterse et al. 2014). The efficacy by which B. bassiana can colonize and induce defense responses in tomato to repel pests is still unknown.

The specific objective of this study was to clarify whether the inoculation of tomato (Solanum lycopersicum) with $B$. bassiana could provide advantages in terms of pest management and plant growth. We hypothesized that colonization may prime tomato plants and initiate host defense responses upon subsequent attack by Bemisia tabaci. To examine this phenomenon, we asked the following questions: (i) is it possible to extract $B$. bassiana sequences from tomato plants by nested PCR; (ii) which tissue exhibits maximum colonization; (iii) can B. bassiana as endophyte affect plant growth; (iv) does colonization affect pest feeding behavior and host choice.

\section{Methods}

\section{Plant, fungi and insects}

Tomato (Solanum lycopersicum) seeds (Hezuo 903) were purchased at the Shanghai Changzhong Tomato Co., Ltd, China. As a standard of sterilization during tests, seeds were sterilized with $1 \% \mathrm{NaClO}$ for 5 min, rinsed three times with sterile distilled water, and dried on sterile filter paper (McKinnon et al. 2017; Rondot and Reineke 2018). The seeds were sown in a sterile nutrient soil (dry sterilization: $75^{\circ} \mathrm{C}$ for $24 \mathrm{~h}$; organic matter $463 \mathrm{~g} / 1000 \mathrm{~g}, \mathrm{~N}+\mathrm{P}+\mathrm{K}$ $5.36 \mathrm{mg} / 1000 \mathrm{~g}$, trace element $1.7 \mu \mathrm{g} / 1000 \mathrm{~g}$; Lianyungang Hengoda Fertilizer Technology Co., Ltd.) and placed in a climate chamber for germination $\left(26 \pm 1^{\circ} \mathrm{C}, \mathrm{RH}=75 \pm 5 \%\right.$, $\mathrm{L}: \mathrm{D}=14: 10$ ). Plants were used in experiments when they reached $20 \mathrm{~cm}$ height.

All tests used the fungus Beauveria bassiana strain Bb252, stored in Biotechnology Center of Southwest University at $-80^{\circ} \mathrm{C}$. It was originally isolated from Chilo suppressalis on maize in Yongchuan District, Chongqing, China and was separated into a single spore. For all tests, Bb252 was grown on potato dextrose agar medium at $28 \pm 1{ }^{\circ} \mathrm{C}$ in darkness. For the tests, $0.1 \%$ Tween- 80 was used to emulsify conidia, and hemocytometer was used to determine spore concentrations.

Insects used in this experiment were Bemisia tabaci (biotype: MED). Insects were initially collected from a vegetable greenhouse in 2016 in Tongnan District, Chongqing, and have been reared in the laboratory for more than 30 generations with tomato as host $\left(26 \pm 1^{\circ} \mathrm{C}, \mathrm{RH}=75 \pm 5 \%\right.$, $\mathrm{L}: \mathrm{D}=14: 10)$.

\section{B. bassiana inoculation treatments and DNA extraction}

Three inoculation methods were performed in these experiments: foliar spraying, root irrigation, and seed dressing (Kasambala et al. 2018). The concentration of B. bassiana used in all treatments was $1 \times 10^{8}$ conidia/ml. Spray application used $10 \mathrm{ml}$ of conidial suspension, evenly targeted onto leaf surfaces by a small hand sprayer. Root irrigation involved application of the suspension on the soil surface with a $10 \mathrm{ml}$ syringe. Seed dressing was done by mixing the seeds with spore suspension which contained $10 \%$ methyl cellulose (Chron Chemicals co., Ltd.) (Harekrushna et al. 2018). Thereafter, the mixtures were shaken on a shaker 
for 3 days to complete the inoculation (Wagner and Lewis 2000). Inoculated seeds were grown in independent seedling trays $(4 \mathrm{~cm} \times 4 \mathrm{~cm})$ and placed in a biochemical incubator at $26 \pm 1{ }^{\circ} \mathrm{C}, \mathrm{RH}=75 \pm 5 \%, \mathrm{~L}: \mathrm{D}=14: 10$.

Plant surfaces were disinfected before DNA sequence extraction. Post inoculation on 3rd day, 7th day, 14th day, and 21st day, plants were sterilized using the same procedure as above for seed disinfection. Then $0.5 \mathrm{~g}$ of plant tissue was ground with liquid nitrogen (Landa et al. 2013). Genomic DNA of B. bassiana was extracted by BioSpin Fungal Genome DNA Assay Kit (Hangzhou Bioer Technology Co. Ltd. BIOER).

\section{Specific nested PCR protocol}

DNA from all subjects was subjected to a two-step nested PCR protocol to isolate $B$. bassiana sequences from tomato plant tissues. This protocol used primers ITS1-F/ITS-4 (5'CTTGTTCGCTATCGGTCTC-3'/5'-TCCGTAGGTGAA CCTGCGG-3') and Bb.fw/ Bb.rv (5'-GAACCTACCTAT CGTTGCTTC-3'/5'-ATTCGAGGTCAACGTTCAG-3') for the first and second round (Quesada-Moraga et al. 2014). PCR reaction system includes $10 \mathrm{mM}$ primers each for $0.5 \mu 1,2 \mu \mathrm{l}$ DNA template, and $22 \mu \mathrm{l}$ T3 Super PCR Mix (TsingKe Biology Technology Co. Ltd.). The reaction procedures were as follows: $98{ }^{\circ} \mathrm{C}$ for $2 \mathrm{~min}, 98^{\circ} \mathrm{C}$ for $10 \mathrm{~s}$, $61{ }^{\circ} \mathrm{C}$ for $10 \mathrm{~s}, 72{ }^{\circ} \mathrm{C}$ for $10 \mathrm{~s}$ for 35 cycles; $72{ }^{\circ} \mathrm{C}$ for $2 \mathrm{~min}$ for first round; second round annealing activity at $55^{\circ} \mathrm{C}$ for $10 \mathrm{~s}$, and residual procedure was consistent with the first round. Finally, PCR products were detected by agarose gel electrophoresis with $2.5 \%$ gel concentration.

\section{Distribution of B. bassiana in plants}

This part was based on the nested PCR test results by three inoculation methods. Inoculation concentrations included $1 \times 10^{8}$ conidia $/ \mathrm{ml}, 1 \times 10^{7}$ conidia $/ \mathrm{ml}, 1 \times 10^{6}$ conidia/ $\mathrm{ml}, 1 \times 10^{5}$ conidia/ml, and $1 \times 10^{4}$ conidia $/ \mathrm{ml}$. The samples were tested seven days after being inoculated. Plant surfaces were sterilized and divided into three parts (root, stem, and leaf). $2 \mathrm{~g}$ (fresh weight) were weighed for each sample, homogenized by grinding, and applied into selective medium $(0.2 \mathrm{~g} / \mathrm{l}$ Chloramphenicol; $0.05 \mathrm{~g} / \mathrm{l}$ Vondodine; $1.2 \mathrm{~g} / \mathrm{l} \mathrm{Kanamycin;} 0.01 \mathrm{~g} / \mathrm{l} \mathrm{Crystal}$ violet; $10 \mathrm{~g} / \mathrm{l} \mathrm{Glucose}$; and $15 \mathrm{~g} / \mathrm{l} \mathrm{Agar}$ ). Plates were incubated at $28 \pm 1{ }^{\circ} \mathrm{C}$ darkness for 7 days, and colony-forming units (CFU) were counted (Chase et al. 1986).

\section{Effect of B. bassiana inoculation on plant growth}

Beauveria bassiana was inoculated by foliar spray and root irrigation in tomato at the above concentrations, and control plants were treated with $0.05 \%$ Tween-80. After inoculation, plants were cultured in a climate chamber for 2 weeks $\left(26 \pm 1{ }^{\circ} \mathrm{C}, \mathrm{RH}=75 \pm 5 \%\right.$, and $\left.\mathrm{L}: \mathrm{D}=14: 10\right)$. Specific growing indices for the determination of root length, stem length (the distance from plant root to the tip of the stem), leaf area, and dry weight were determined after ovendrying samples at $50{ }^{\circ} \mathrm{C}$ for $96 \mathrm{~h}$ (Kasambala et al. 2018). Each group included five individual samples.

\section{Potted plant investigations with Bemisia tabaci}

To evaluate whitefly behavioral responses to $B$. bassiana inoculated plants, a random-selection test was conducted using inoculated and uninoculated plants at the same growth stage. B. bassiana suspension was sprayed on the leaves or applied to the root as described above. For exposure to the insects, treated plants were placed in an insect cage $(20 \mathrm{~cm} \times 20 \mathrm{~cm} \times 40 \mathrm{~cm})$ together with control plants $(0.05 \%$ Tween-80). Thirty B. tabaci adults were released in the cage and were allowed to settle and feed for 5 days on the plants. To analyze the feeding preference, the amount of feeding was determined by counting the feeding marks on the leaves. A filter paper with Bromocresol green was placed under the leaves, producing a metachromatism with honeydew caused by the whitefly feeding process (Qiu et al. 2014). Adult distribution on plants was checked each day, and feeding and egg laying were quantified five days after the start of the experiment. All tests were replicated four times.

\section{Y-tube olfactometer evaluation for B. tabaci preference}

Dual-choice tests for B. tabaci preference between B. bassi$a n a$-treated and untreated tomato plants were carried out using a Y-shaped tube. Preliminary testing was conducted using $1 \mathrm{~g}$ of fresh spray inoculated or uninoculated leaves, placed at the end of the tube. Air was pumped through an activated charcoal filter to replace the Y-tube air at the rate of $2500 \mathrm{ml} / \mathrm{min}$ for $10 \mathrm{~min}$. Fifteen whitefly adults were released in the top of the Y-tube. The number of insects present at each arm was recorded after $15 \mathrm{~min}$. Further testing was conducted using $1 \mathrm{~g}$ of fresh leaves soaked in anhydrous ethanol for $12 \mathrm{~h}$. Leaf treatments included B. bassiana inoculation, leaves fed upon by the whitefly, and $0.05 \%$ Tween- 80 sprayed as control. Air filtration and insect release were consistent with the previous tests, with the difference that $50 \mu \mathrm{l}$ of $10 \%$ ethyl alcohol extracts from the treated and untreated leaves was added at the tube end (Schettino et al. 2017). The experiment was designed as pairwise coupling, with statistics collected at $15 \mathrm{~min}$ intervals. Ten consecutive statistics were obtained, and each treatment was repeated 10 times. 


\section{Statistical analysis}

All data were subjected to one-way ANOVA analysis, the Tukey's test was used to make multiple comparisons of the mean $(P<0.05)$, and paired trial was performed using $t$ test. SPSS statistical software, version 21.0 was used for data analyses. Figures were produced using Origin version 2018.

\section{Results}

\section{B. bassiana colonization efficiency}

Validation studies show that nested PCR did not detect any B. bassiana sequences in the technical control (Fig. 1). Therefore, the plant surface disinfection procedure used in this study is effective against eliminating the interference with $B$. bassiana in vitro. Detection results show that colonization efficiency reached $100 \%$ in 14 days when leaves were inoculated by spraying (Fig. 2). The seed dressing inoculation resulted in the lowest colonization rate which gradually dropped to zero with time. All amplified sequences were highly related to B. bassiana ITS sequences (KX091133) by NCBI blast (Fig. 3).

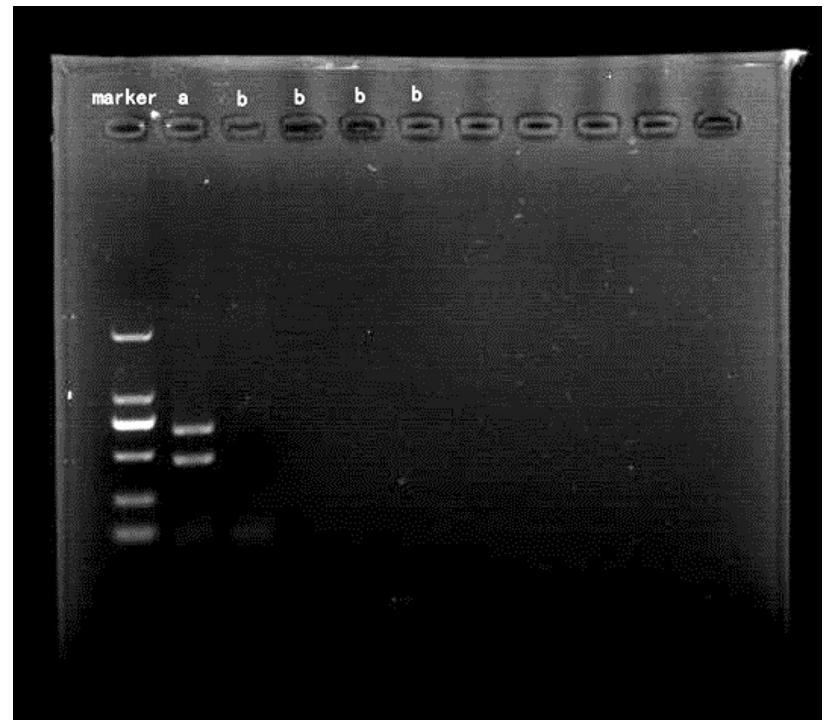

Fig. 1 Detection of surface disinfection effect of tomato plants. $a$ unsterilized; $b$ sterilized. In unsterilized samples, the bands indicate the sequence of B. bassiana. After sterilized, no B. bassiana sequence was detected in tomatoes

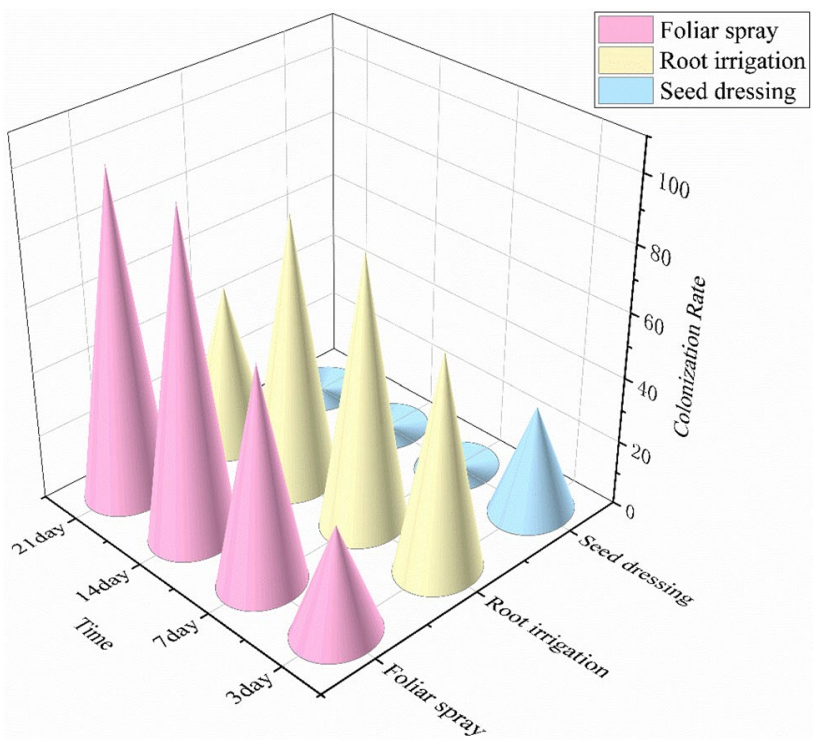

Fig. 2 Comparison of colonization rate of tomato by B. bassiana

\section{Distribution of $B$. bassiana in plants}

B. bassiana could successfully colonize multiple tissues and presented a systemic distribution in the plant (Fig. 4). However, the colonization was uneven and appears to be

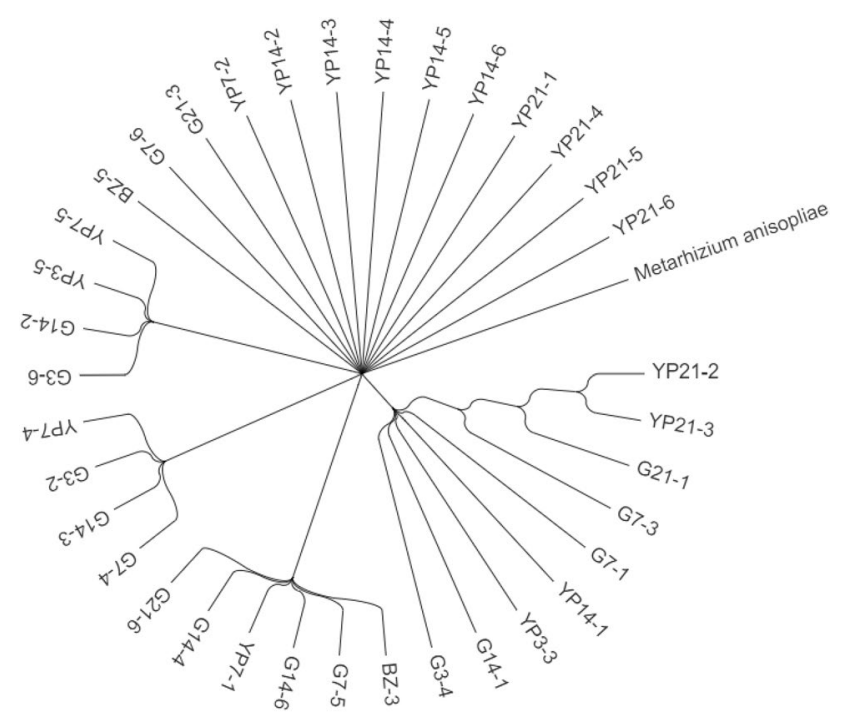

Fig. 3 Comparison of homology between nested PCR amplification of $B$. bassiana. Phylogenetic tree constructed by Maximum likelihood method. The letters G, BZ, and YP represent the inoculation methods of rooting, seed dressing, and leaf spraying, respectively 
Fig. 4 Tomato tissues colonized by $B$. bassiana
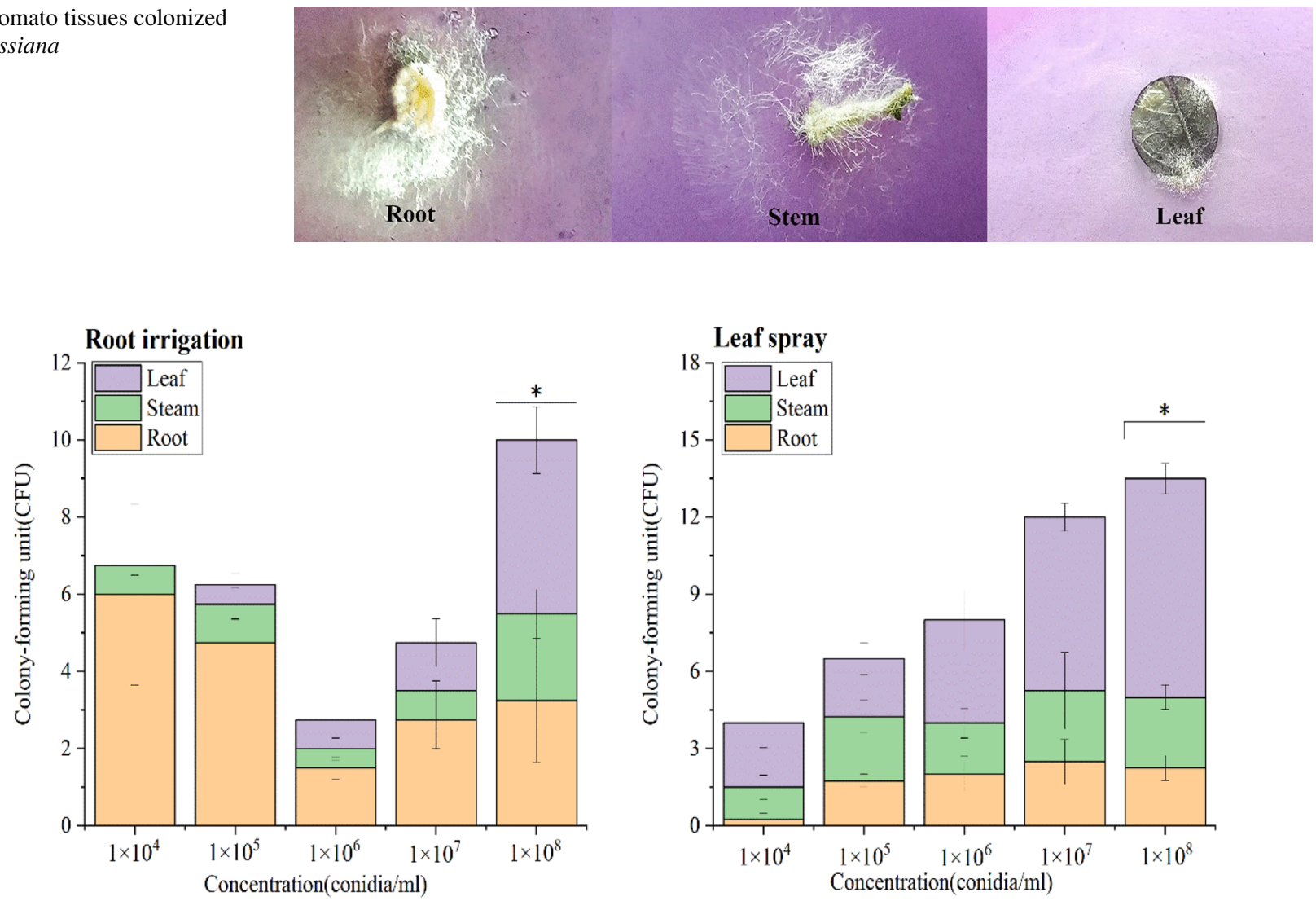

Fig. 5 Comparison of the efficiency of colonization of different plant parts by B. bassiana at different inoculation rates and treatment methods. The asterisk indicates significant difference with other treatments

preferentially localized in the inoculation region. In foliar sprays, B. bassiana colonization focused on mesophyll tissues. In the treatment at $1 \times 10^{8}$ conidia/ml, the number of colonies isolated from the leaf tissue reached $8.5 \pm 2.02$ per $2 \mathrm{~g}$ of leaf tissue $\left(F_{4,19}=2.779, P=0.045\right)$. With the root irrigation method, fungi were mostly found in the stem or in the root (Fig. 5).

\section{Effect of B. bassiana inoculation on plant growth}

Inoculation with fungi had no negative effects on plant growth with any of the tested methods. Although artificial inoculation promotes plant growth in some cases, the roots, stems, leaf area, and dry weight did not show significant differences from the untreated control (Fig. 6). Nevertheless, principal component analysis showed a clear result with the foliar spray method (PC1 55.7\%, PC2 34.7\%, Fig. 7). Multifactor comprehensive analysis demonstrated that leaf spraying receives a greater impact on plant growth, particularly when using $1 \times 10^{5}$ conidia/ml, with the highest contribution score (2.645). Further analysis indicates that the root receives the biggest benefit (Eigenvalues $=2.228$ ) and plant dry weight the lowest $($ Eigenvalues $=0.404)$.

\section{Investigations with potted plants}

The selectivity test indicates that $B$. tabaci adults tend to feed on uninoculated plants. This tendency did not result in significant differences at higher concentrations (Fig. 8). It is worth noting that when using leaf spray, there was an imbalanced distribution of B. tabaci eggs. Using $1 \times 10^{8}$ conidia/ml $(P=0.003), 1 \times 10^{7}$ conidia/ml $(P<0.001)$, and $1 \times 10^{4}$ conidia/ml $(P<0.001)$, the numbers of oviposited eggs were $7.25 \pm 3.49 ; 45.5 \pm 12.35$; and $16.25 \pm 10.47$ in the treatments, while the numbers in the respective control groups were significantly higher $(33.25 \pm 6.49$; $94.75 \pm 12.23$; and $75.00 \pm 18.47)$. 
A
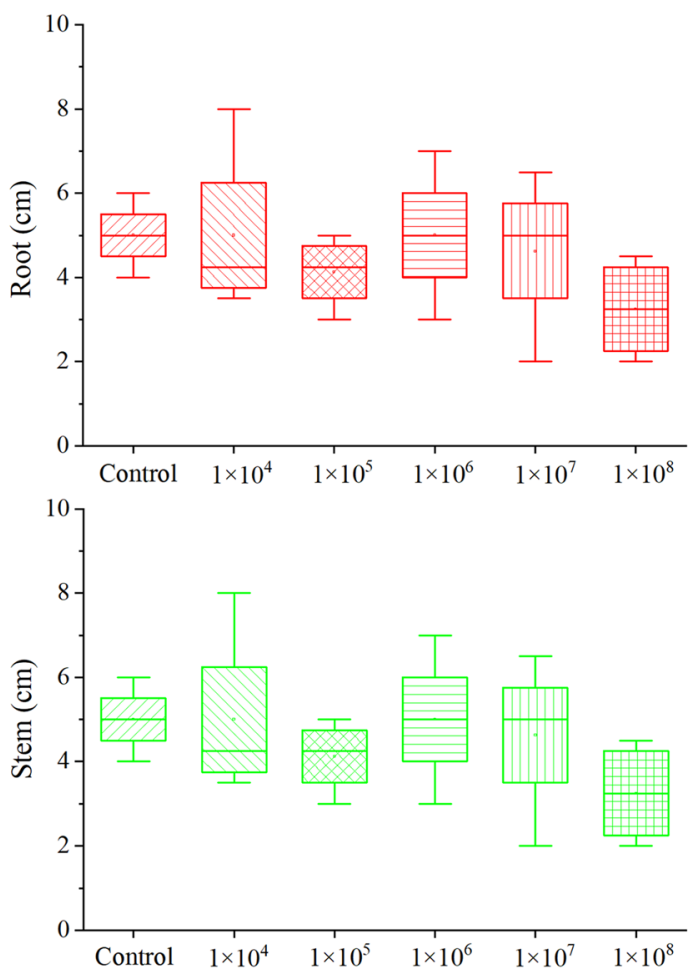

Leaf spray
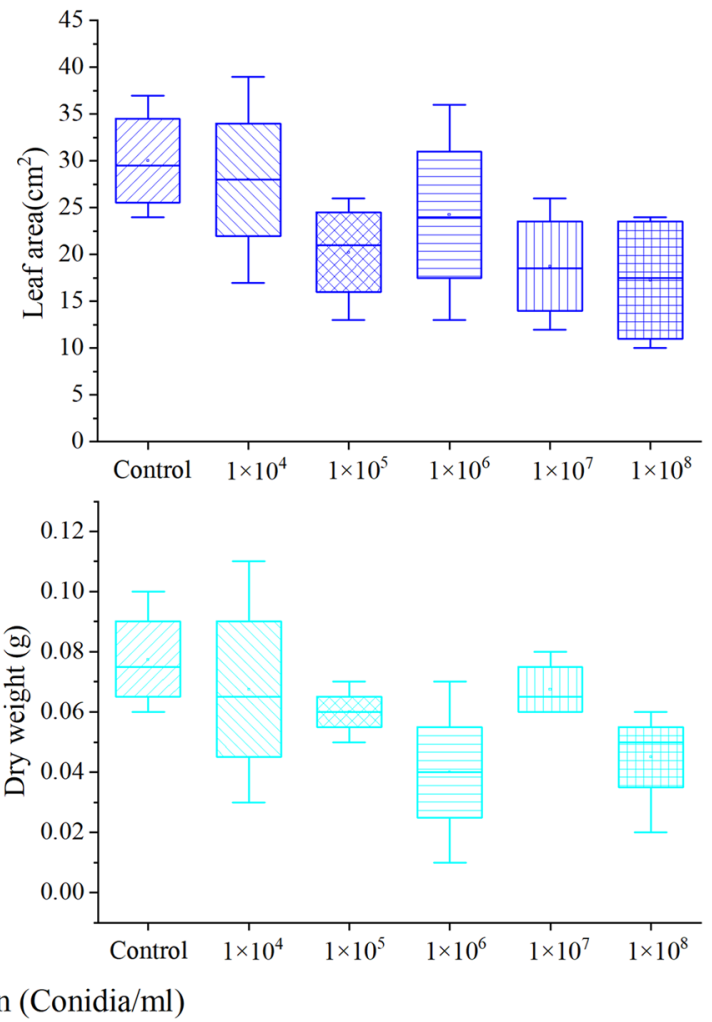

B
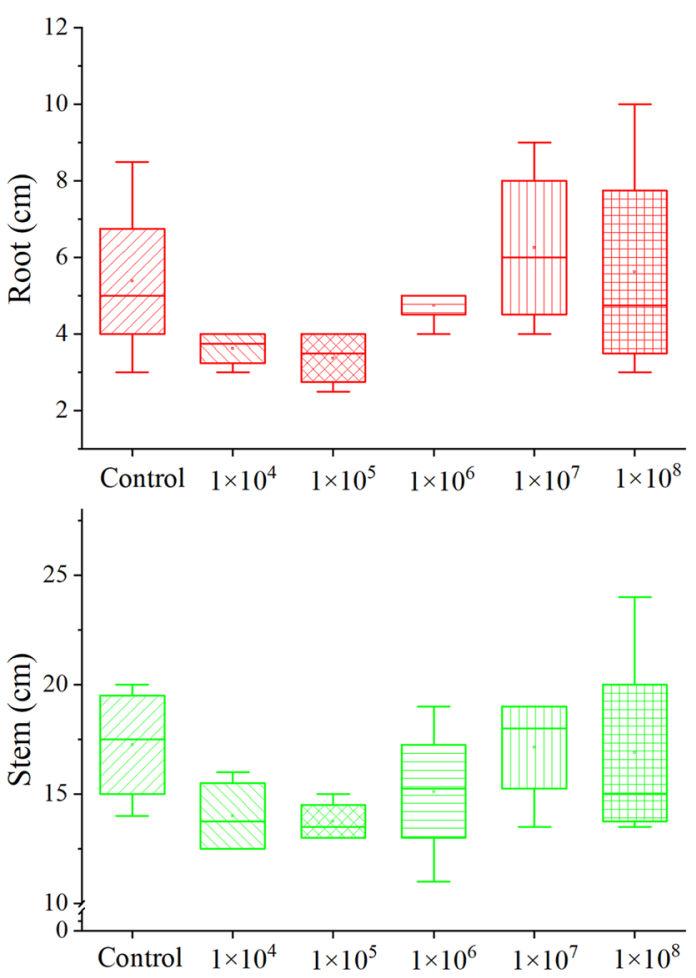

Root irrigation
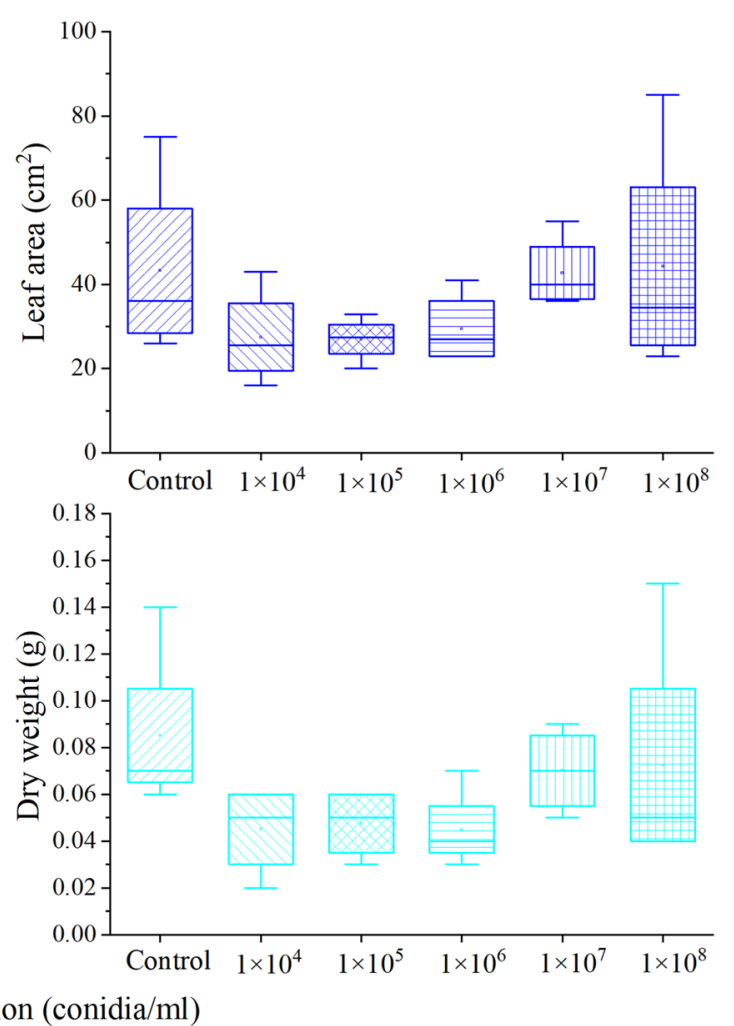

Fig. 6 Growth indexes of tomato treated with B. bassiana. a B. bassiana inoculated by foliar spray; $\mathbf{b}$ B. bassiana inoculated by root irrigation 
Fig. 7 Principal component analysis of growth indicators of tomatoes treated with different inoculation methods

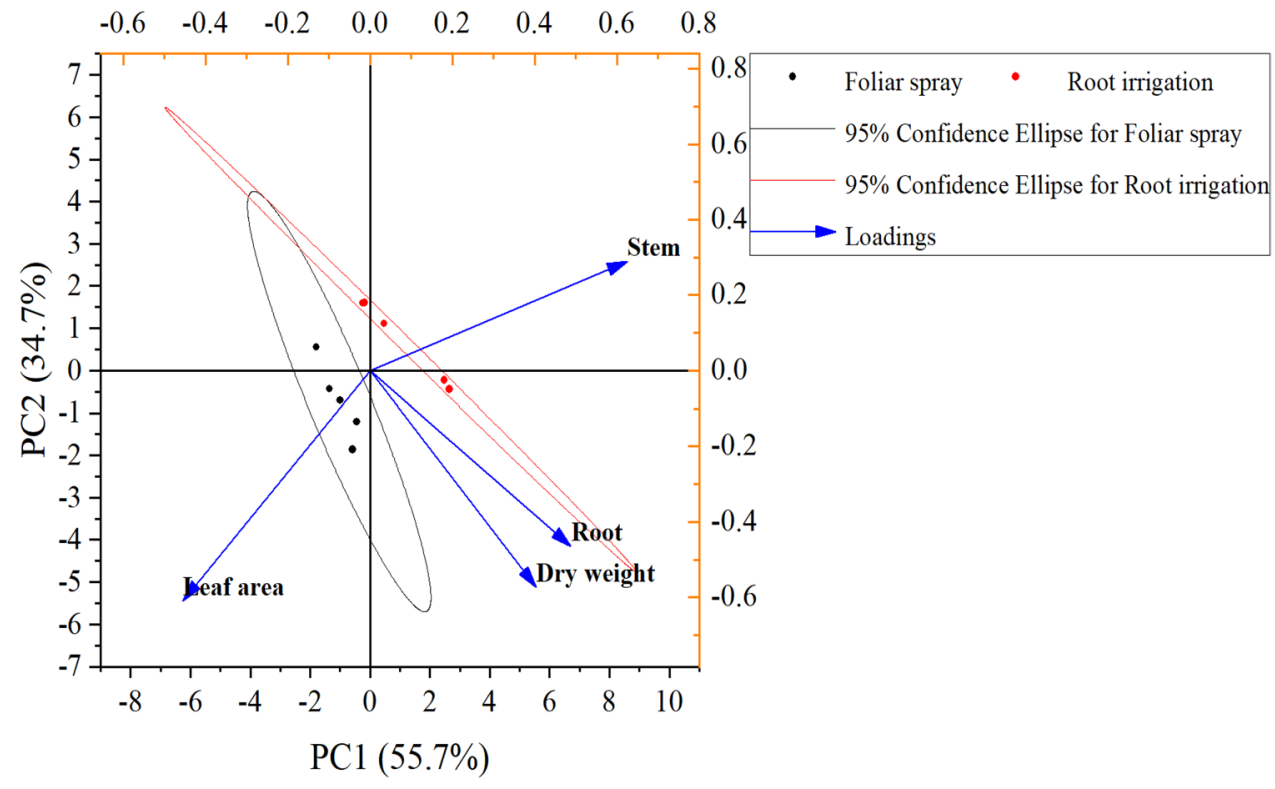

\section{Y-tube selective evaluation}

In order to eliminate the possible interference with insectfeeding choice by B. bassiana or plant nutritional factors, fresh leaves and plant extracts were used in this part. Specifically, $79.2 \%$ of insects chose uninoculated leaves, while only $20.8 \%$ selected $B$. bassiana-treated leaves $(t=12.74$, $P<0.0001)$. As for plant extracts, the numbers of insects in the control group were significantly higher than that in the $B$. bassiana inoculation treatment $(80.5 \%$ vs. $19.5 \%)$ or in the insect-feeding treatment (72.1\% vs. $27.9 \%)$ (Fig. 9). Comparing the treatment with fungus-inoculated leaves (70.4\%) and insect-feeding leaves (29.6\%), the whiteflies prefer to select the former $(P<0.05)$.

\section{Discussion}

An initial objective of this project was to identify whether B. bassiana colonization of plants influences the feeding preference of insects. This fungus can enter tomato tissues randomly by inoculation treatments without negatively affecting the plant growth. Simultaneously, plants containing $B$. bassiana can reduce insect attraction.

We demonstrate that B. bassiana sequences can be detected reliably by the nested PCR technique in tomato. Previous studies have well ascertained that the infestation by entomogenous fungi is primarily achieved by growing hyphae in the direction of the cuticula (Anling et al. 2016). But inside the organism, the status of the invaded fungi is still unclear. It is speculated that it may enter the plant in the form of spores (McKinnon et al. 2017). In our results, the leaf spraying received a better colonization efficiency, and may be due to the stoma structures, which also has been confirmed to be an excellent exchange channel in a variety plants (Quesada-Moraga et al. 2006; Shikano et al. 2017). B. bassiana spore grow randomly across the surfaces of tomato tissues. However, if a natural opening (e.g., stomata) is encountered, $B$. bassiana may enter and invade the plant (Wagner and Lewis 2000).

After the B. bassiana enters the plant, the distribution of the fungus was observed to be uneven. Fungal spread is principally based on passive transmission, which leads to a random diffusion in tissue (Powell et al. 2009). The main force that drives $B$. bassiana migration is water, which is a carrier in the plant transpiration (Brownbridge et al. 2012; Garrido-Jurado et al. 2016). Nevertheless, the distance and the number of translocations is also limited by several physiological factors (Quesada-Moraga et al. 2014; Raad 2016), resulting in a high probability of B. bassiana preferential localization to the inoculation site.

Plant growth was affected by the growth medium (sterile soil, non-sterile soil, and vermiculite), but not by the inoculation method (Vänninen et al. 2000). A few years ago, Jaber and Enkerli (2017) found that entomogenous fungi that colonize plants can promote the growth of Vicia faba. Although small differences were observed in our study among the growth indicators, the PCA result showed that leaf spray inoculation stimulated an increase in plant growth. This may be due to the fact that the foliar spray results in a 

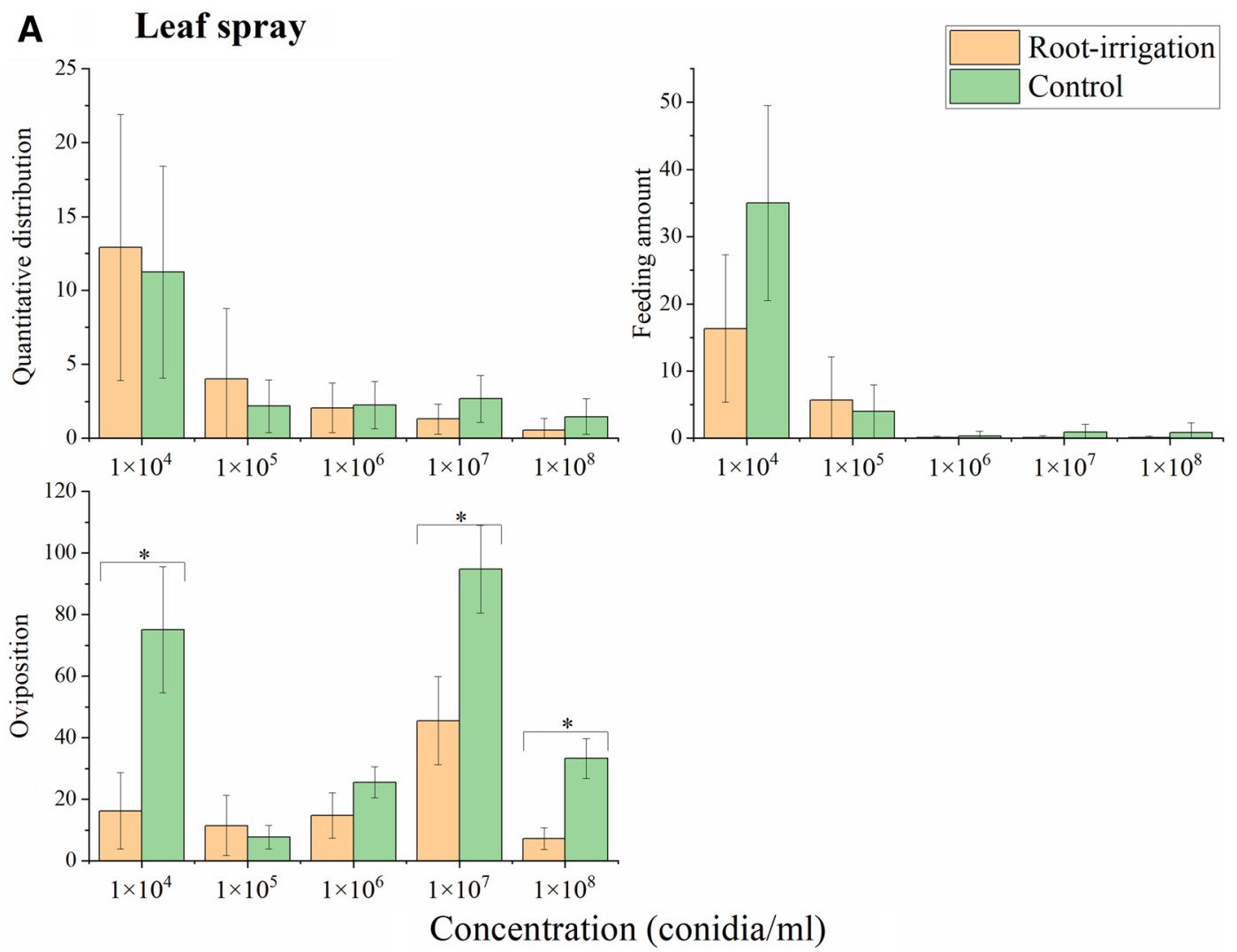

B Root irrigation
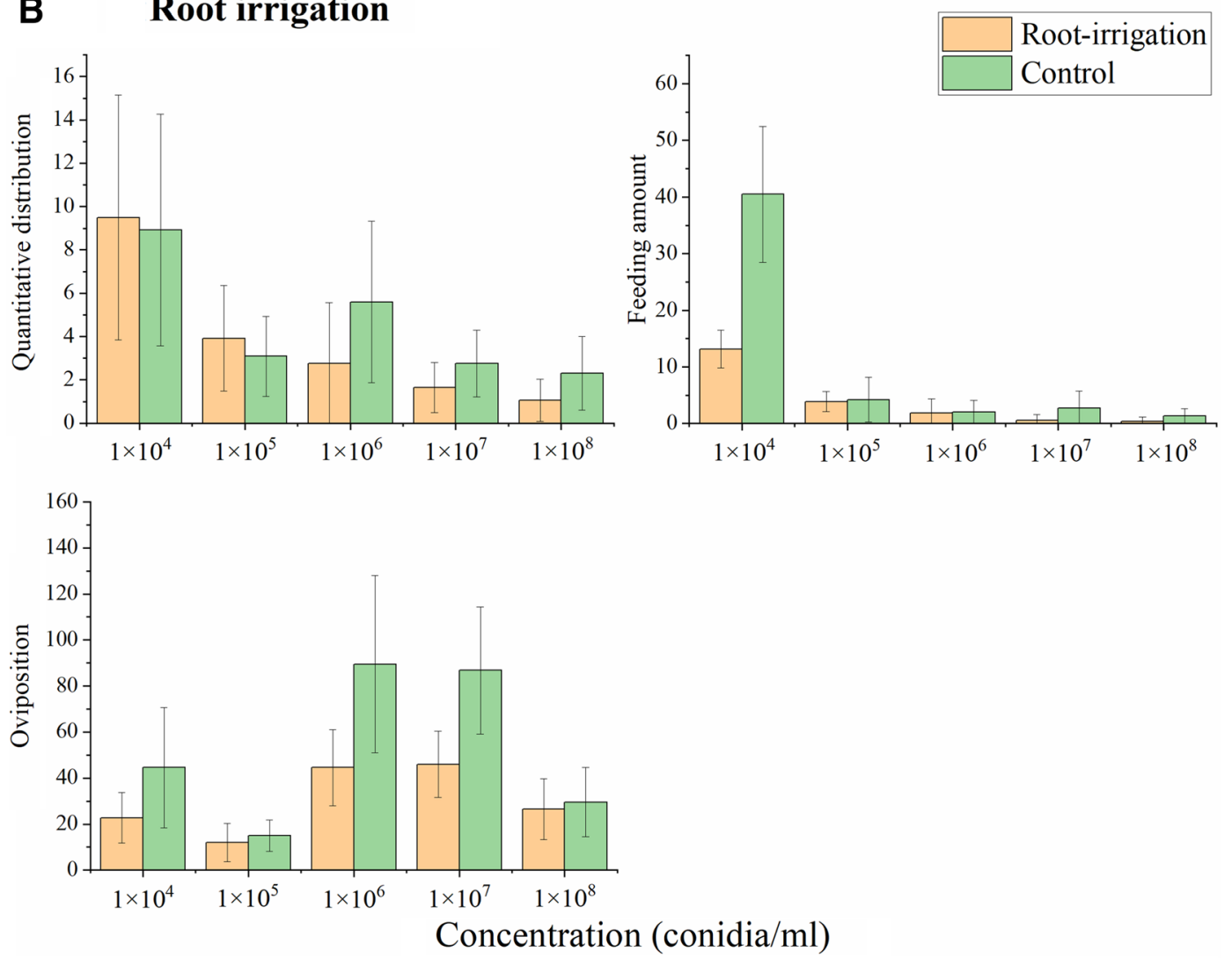
4Fig. 8 Effects of B. bassiana inoculation method and spore concentrations on the feeding and oviposition of B. tabaci. a B. bassiana inoculated by foliar spray. $\mathbf{b} B$. bassiana inoculated by root irrigation. The pictures show a difference of whitefly preference, feed intake, and the number of eggs on plants inoculated with $B$. bassiana

larger contact region, enhancing the interaction (Jaber and Enkerli 2017; Senthilraja et al. 2010). On the other hand, $B$. bassiana had low persistence in soils and will reduce contact time with plants (Vänninen et al. 2000). In addition, the driving force behind plant growth is mainly based on absorption and utilization of nutrients from the soils (Weisany et al. 2014). B. bassiana promotion of plant growth also may depend on nutrient exchange, which allows the plant to source organic nitrogen while providing a carbon source as return (Behie et al. 2017; Wang et al. 2013). It is believed that entomopathogenic fungi evolved from symbiotic fungi that were plant associates, and that arthropod pathogenicity is a more recently acquired adaptation (Barelli et al. 2016; Gao et al. 2011).

The presence of $B$. bassiana in plants can also be recognized by plants (Boller and Felix 2009). The chitin from fungi and $\beta$-glucans from fungi and oomycetes are clear examples of identified features (Mauch-Mani et al. 2017). These molecules are also present in beneficial microbes where the term microbe-associated molecular pattern (MAMP) is used (Pieterse et al. 2014). Through recognition by pattern recognition receptors, $B$. bassiana also can induce plant systemic defense responses (Eleftherianos et al. 2013; Ownley et al. 2010). This may be one important reason why insects have a strong preference for uninoculated plants. Induced plants transform metabolic compounds to reduce or inhibit feeding by most plant-feeding insects (Hokkanen and Menzler-Hokkanen 2017; Menjivar et al. 2011). Activation of plant defense responses following response priming is associated with hormone metabolism and signal transduction (Rivera et al. 2017). It has been documented that volatilization of salicylic acid (SA), jasmonic acid (JA), ethylene (ET) and other substances could mediate metabolite components and content (Martorana et al. 2017). Widespread plant secondary metabolite compounds include terpenes, acylsugars, alkaloids (Bleeker et al. 2012; Luan et al. 2013; Shepherd and Wagner 2007), and flavonoids, which constitute the largest and most prominent classes of plant-derived control agents associated with insect foraging and oviposition preference (Su et al. 2018). In the meantime, these substances even can be used as identification signals to attract natural enemies (Rasmann and Turlings 2007; Xiaoping et al. 2017). Nevertheless, it is accepted that the complexity of plant defense responses requires abundant amount of energy, which creates an antagonistic relationship with plant growth (Shiojiri et al. 2001; Tuomi et al. 1988). Due to the restrictions on plant nutritional supply, the defenses are activated by a diversity of mechanisms and are kept at a low level for a long period (Koricheva 2002; Somlyai et al. 1988).

These findings may help us to excavate multiple potential applications for biocontrol fungi. B. bassiana is not only directly acting as a mortality factor on insects, but is also providing protection for plants by reducing pest feeding. This potential could be of great significance in ecological pest management. A still unanswered question is the mechanism of plant resistance. Further investigations, which take this defense response into account, need to be undertaken.
Fig. 9 The preference of $B$. tabaci to tomato leaf extracts from differentially treated plants. The asterisks indicate significant difference in the preference of $B$. tabaci

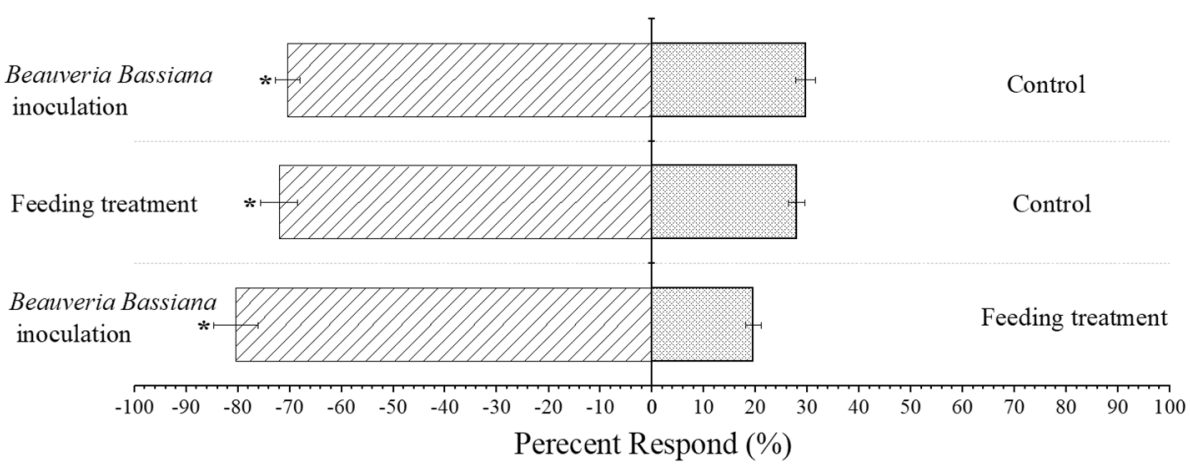


Acknowledgements This research was supported by the National Key R\&D Program of China (2018YFD0200501), the Science and Technology Projects in Chongqing Tobacco Company (NY20180401070009). We also thank Prof. Heikki Hokkanen and Ingeborg Menzler-Hokkanen (Department of Environmental and Biological Sciences, University of Eastern Finland, Finland) for assistance with improving the manuscript.

Open Access This article is licensed under a Creative Commons Attribution 4.0 International License, which permits use, sharing, adaptation, distribution and reproduction in any medium or format, as long as you give appropriate credit to the original author(s) and the source, provide a link to the Creative Commons licence, and indicate if changes were made. The images or other third party material in this article are included in the article's Creative Commons licence, unless indicated otherwise in a credit line to the material. If material is not included in the article's Creative Commons licence and your intended use is not permitted by statutory regulation or exceeds the permitted use, you will need to obtain permission directly from the copyright holder. To view a copy of this licence, visit http://creativecommons.org/licenses/by/4.0/.

\section{References}

Aime S, Alabouvette C, Steinberg C et al (2013) The endophytic strain Fusarium oxysporum Fo47: a good candidate for priming the defense responses in tomato roots. Mol Plant Microbe Interact 26(8):918-926. https://doi.org/10.1094/MPMI-12-12-0290-R

Akello J, Sikora R (2012) Systemic acropedal influence of endophyte seed treatment on Acyrthosiphon pisum and Aphis fabae offspring development and reproductive fitness. Biol Control 61(3):215-221. https://doi.org/10.1016/j.biocontrol .2012 .02 .007

Akello J, Dubois T, Coyne D et al (2008) Effect of endophytic Beauveria bassiana on populations of the banana weevil, Cosmopolites sordidus, and their damage in tissue-cultured banana plants. Entomol Exp Appl 129(2):157-165. https://doi.org/10. 1111/j.1570-7458.2008.00759.x

Allegrucci N, Velazquez MS, Russo ML et al (2018) Endophytic colonisation of tomato by the entomopathogenic fungus Beauveria bassiana: the use of different inoculation techniques and their effects on the tomato leafminer Tuta absoluta (Lepidoptera: Gelechiidae). J Plant Prot Res 1:15-20. https://doi.org/10.1515/ jppr-2017-0045

Anling H, Zhaofeng T, Xiwu G et al (2016) Joint toxicity of Beauveria bassiana and two insect growth regulators on beet armyworm, Spodoptera exigua (Hübner). Plant Dis Pests 7:1-12

Barelli L, Moonjely S, Behie S et al (2016) Fungi with multifunctional lifestyles: endophytic insect pathogenic fungi. Plant Mol Biol 90(6):657-664. https://doi.org/10.1007/s11103-015-0413-z

Behie S, Moreira C, Sementchoukova I et al (2017) Carbon translocation from a plant to an insect-pathogenic endophytic fungus. Nat Commun 8:14245. https://doi.org/10.1038/ncomms14245

Bleeker P, Mirabella R, Diergaarde P et al (2012) Improved herbivore resistance in cultivated tomato with the sesquiterpene biosynthetic pathway from a wild relative. Proc Natl Acad Sci 109(49):20124-20129. https://doi.org/10.1073/pnas.12087 56109

Boller T, Felix G (2009) A renaissance of elicitors: perception of microbe-associated molecular patterns and danger signals by pattern-recognition receptors. Annu Rev Plant Biol 60:379-406. https://doi.org/10.1146/annurev.arplant.57.032905.105346

Brownbridge M, Reay S, Nelson T et al (2012) Persistence of Beauveria bassiana (Ascomycota: Hypocreales) as an endophyte following inoculation of radiata pine seed and seedlings. Biol Control 61(3):194-200. https://doi.org/10.1016/j.biocontrol .2012.01.002

Chase A, Osborne L, Ferguson V (1986) Selective isolation of the entomopathogenic fungi Beauveria bassiana and Metarhizium anisopliae from an artificial potting medium. Fla Entomol 69(2):285-292. https://doi.org/10.2307/3494930

Cherry AJ, Banito A, Djegui D et al (2004) Suppression of the stemborer Sesamia calamistis (Lepidoptera; Noctuidae) in maize following seed dressing, topical application and stem injection with African isolates of Beauveria bassiana. Int J Pest Manag 50(1):67-73. https://doi.org/10.1080/09670870310001637426

Eleftherianos I, Atri J, Accetta J et al (2013) Endosymbiotic bacteria in insects: guardians of the immune system? Front Plant Physiol 4:46. https://doi.org/10.3389/fphys.2013.00046

Gao Q, Jin K, Ying S et al (2011) Genome sequencing and comparative transcriptomics of the model entomopathogenic fungi Metarhizium anisopliae and M acridum. PLoS Genet 7(1):e1001264. https ://doi.org/10.1371/journal.pgen.1001264

Garrido-Jurado I, Resquín-Romero G, Amarilla S et al (2016) Transient endophytic colonization of melon plants by entomopathogenic fungi after foliar application for the control of Bemisia tabaci Gennadius (Hemiptera: Aleyrodidae). J Pest Sci 90(1):319-330. https://doi.org/10.1007/s10340-016-0767-2

Harekrushna S, Totan A, Arup KM et al (2018) Novel Trichoderma strains isolated from tree barks as potential biocontrol agents and biofertilizers for direct seeded rice. Microbiol Res 214:83-90. https://doi.org/10.1016/j.micres.2018.05.015

Hokkanen HMT, Menzler-Hokkanen I (2017) The use of entomopathogenic fungi in the insect pest management of Brassica oilseed crops. CABI, Boston, pp 373-382

Jaber L, Enkerli J (2017) Fungal entomopathogens as endophytes: can they promote plant growth? Biocontrol Sci Technol 27(1):28-41. https://doi.org/10.1080/09583157.2016.1243227

Jaber L, Ownley B (2018) Can we use entomopathogenic fungi as endophytes for dual biological control of insect pests and plant pathogens? Biol Control 116:36-45. https://doi.org/10.1016/j. biocontrol.2017.01.013

Jaenike J (1990) Host specialization in phytophagous insects. Annu Rev Ecol Syst 21(21):243-273. https://doi.org/10.1146/annur ev.ecolsys.21.1.243

Kasambala D, Vega F, Klingen I (2018) Establishment of the fungal entomopathogen Beauveria bassiana as an endophyte in sugarcane, Saccharum officinarum. Fungal Ecol 35:70-77. https://doi. org/10.1016/j.funeco.2018.06.008

Koricheva J (2002) Meta-analysis of sources of variation in fitness costs of plant antiherbivore defenses. Ecology 83(1):176-190. https:// doi.org/10.1890/0012-9658(2002)083[0176:MAOSOV]2.0.CO;2

Kuc J (1987) Plant immunization and its applicability for disease control, vol 255. Wiley, New York

Landa B, Lopez-Diaz C, Jimenez-Fernandez D et al (2013) In-planta detection and monitorization of endophytic colonization by a Beauveria bassiana strain using a new-developed nested and quantitative PCR-based assay and confocal laser scanning microscopy. J Invertebr Pathol 114(2):128-138. https://doi.org/10.1016/j. jip.2013.06.007

Luan J, Yao D, Zhang T et al (2013) Suppression of terpenoid synthesis in plants by a virus promotes its mutualism with vectors. Ecology 16(3):390-398. https://doi.org/10.1111/ele.12055

Martinez-Medina A, Flors V, Heil M et al (2016) Recognizing plant defense priming. Trends Plant Sci 21(10):818-822. https://doi. org/10.1016/j.tplants.2016.07.009

Martorana L, Foti M, Rondoni G et al (2017) An invasive insect herbivore disrupts plant volatile-mediated tritrophic signalling. J Pest Sci 90(4):1079-1085. https://doi.org/10.1007/s10340-017-0877-5 
Mauch-Mani B, Baccelli I, Luna E et al (2017) Defense priming: an adaptive part of induced resistance. Annu Rev Plant Biol 68:485512. https://doi.org/10.1146/annurev-arplant-042916-041132

McCormick A, Reinecke A, Gershenzon J et al (2016) Feeding experience affects the behavioral response of polyphagous gypsy moth caterpillars to herbivore-induced poplar volatiles. J Chem Ecol 42(5):382-393. https://doi.org/10.1007/s10886-016-0698-7

McKinnon A, Saari S, Moran-Diez M et al (2017) Beauveria bassiana as an endophyte: a critical review on associated methodology and biocontrol potential. Biocontrol 62(1):1-17. https://doi. org/10.1007/s10526-016-9769-5

Menjivar RD, Cabrera JA, Kranz J et al (2011) Induction of metabolite organic compounds by mutualistic endophytic fungi to reduce the greenhouse whitefly Trialeurodes vaporariorum (Westwood) infection on tomato. Plant Soil 352(1-2):233-241. https://doi. org/10.1007/s11104-011-0991-8

Ownley B, Griffin M, Klingeman W et al (2008) Beauveria bassiana: endophytic colonization and plant disease control. J Invertebr Pathol 98(3):267-270. https://doi.org/10.1016/j.jip.2008.01.010

Ownley B, Gwinn K, Vega F (2010) Endophytic fungal entomopathogens with activity against plant pathogens: ecology and evolution. Biocontrol 55(1):113-128. https://doi.org/10.1007/s1052 6-009-9241-x

Pagadala D, Kempraj V, Aurade R et al (2014) Oviposition site-selection by Bactrocera dorsalis is mediated through an innate recognition template tuned to $\gamma$-octalactone. PLoS ONE 9(1):e85764. https://doi.org/10.1371/journal.pone.0085764

Pieterse C, Zamioudis C, Berendsen R et al (2014) Induced systemic resistance by beneficial microbes. Annu Rev Phytopathol 52:347375. https://doi.org/10.1146/annurev-phyto-082712-102340

Pineda A, Zheng S, Van-Loon JJ et al (2010) Helping plants to deal with insects: the role of beneficial soil-borne microbes. Trends Plant Sci 15(9):507-514. https://doi.org/10.1016/j.tplan ts.2010.05.007

Posada F, Aime M, Peterson S et al (2007) Inoculation of coffee plants with the fungal entomopathogen Beauveria bassiana (Ascomycota: Hypocreales). Mycol Res 111(6):748-757. https://doi. org/10.1016/j.mycres.2007.03.006

Powell W, Klingeman W, Ownley B et al (2009) Evidence of endophytic Beauveria bassiana in seed-treated tomato plants acting as a systemic entomopathogen to larval Helicoverpa zea (Lepidoptera: Noctuidae). J Entomol Sci 44(44):391-396. https://doi.org/ 10.1111/j.1744-7917.2009.01277.x

Qiu H, Lu L, Zhang C et al (2014) Pathogenicity of individual isolates of entomopathogenic fungi affects feeding preference of red imported fire ants Solenopsis invicta. Biocontrol Sci Technol 24(11):1286-1296. https://doi.org/10.1080/09583157.2014.93331 3

Quesada-Moraga E, Landa B, Munoz-Ledesma J et al (2006) Endophytic colonisation of opium poppy, Papaver somniferum, by an entomopathogenic Beauveria bassiana strain. Mycopathologia 161(5):323-329. https://doi.org/10.1007/s11046-006-0014-0

Quesada-Moraga E, Munoz-Ledesma F, Santiago-Alvarez C (2009) Systemic protection of Papaver somniferum L. against Iraella luteipes (Hymenoptera: Cynipidae) by an endophytic strain of Beauveria bassiana (Ascomycota: Hypocreales). Environ Entomol 38(3):723-730. https://doi.org/10.1603/022.038.0324

Quesada-Moraga E, Lopez-Diaz C, Landa B (2014) The hidden habit of the entomopathogenic fungus Beauveria bassiana: First demonstration of vertical plant transmission. PLoS ONE 9(2):e89278. https://doi.org/10.1371/journal.pone.0089278

Raad M (2016) Plant-mediated interactions between the entomopathogenic fungus Beauveria bassiana, insect herbivores and a plant pathogen. Dissertation, Lincoln University
Rasmann S, Turlings T (2007) Simultaneous feeding by aboveground and belowground herbivores attenuates plant-mediated attraction of their respective natural enemies. Ecology 10(10):926-936. https://doi.org/10.1111/j.1461-0248.2007.01084.x

Rivera M, Pelz-Stelinski K, Martini X et al (2017) Bacterial phytopathogen infection disrupts belowground plant indirect defense mediated by tritrophic cascade. Ecol Evol 7(13):4844-4854. https ://doi.org/10.1002/ece3.3052

Rondot Y, Reineke A (2018) Endophytic Beauveria bassiana in grapevine Vitis vinifera (L.) reduces infestation with piercing-sucking insects. Biol Control 116:82-89. https://doi.org/10.1016/j.bioco ntrol.2016.10.006

Schettino M, Grasso D, Weldegergis B et al (2017) Response of a predatory ant to volatiles emitted by aphid- and caterpillar-infested cucumber and potato plants. J Chem Ecol 43(10):1007-1022. https://doi.org/10.1007/s10886-017-0887-z

Senthilraja G, Anand T, Durairaj C et al (2010) A new microbial consortia containing entomopathogenic fungus, Beauveria bassiana and plant growth promoting rhizobacteria, Pseudomonas fluorescens for simultaneous management of leafminers and collar rot disease in groundnut. Biocontrol Sci Technol 20(5):449-464. https://doi.org/10.1080/09583150903576949

Shepherd R, Wagner G (2007) Phylloplane proteins: emerging defenses at the aerial frontline? Trends Plant Sci 12(2):51-56. https://doi. org/10.1016/j.tplants.2006.12.003

Shikano I (2017) Evolutionary ecology of multitrophic interactions between plants, insect herbivores and entomopathogens. J Chem Ecol 43(6):586-598. https://doi.org/10.1007/s1088 6-017-0850-z

Shikano I, Rosa C, Tan C et al (2017) Tritrophic iInteractions: microbe-mediated plant effects on insect herbivores. Annu Rev Phytopathol 55:313-331. https://doi.org/10.1146/annurev-phyto -080516-035319

Shiojiri K, Takabayashi J, Yano S et al (2001) Infochemically mediated tritrophic interaction webs on cabbage plants. Popul Ecol 43(1):23-29. https://doi.org/10.1007/p100012011

Shivaramu S, Kempraj V, Anjinappa R et al (2017) What signals do herbivore-induced plant volatiles provide conspecific herbivores? Arthropod Plant Interact 11(6):815-823. https://doi.org/10.1007/ s11829-017-9536-2

Slaughter A, Daniel X, Flors V et al (2012) Descendants of primed Arabidopsis plants exhibit resistance to biotic stress. Plant Physiol 158(2):835-843. https://doi.org/10.1104/pp.111.191593

Somlyai G, Solt A, Hevesi M et al (1988) The relationship between the growth rate of Pseudomonas syringae pathovars and the hypersensitive reaction in tobacco. Physiol Mol Plant Pathol 33(3):473482. https://doi.org/10.1016/0885-5765(88)90012-4

Song Y, Chen D, Lu K et al (2015) Enhanced tomato disease resistance primed by arbuscular mycorrhizal fungus. Front Plant Sci 6(786):786. https://doi.org/10.3389/fpls.2015.00786

Su Q, Chen G, Mescher M et al (2018) Whitefly aggregation on tomato is mediated by feeding-induced changes in plant metabolites that influence the behavior and performance of conspecifics. Funct Ecol 32(5):1180-1193. https://doi.org/10.1111/1365-2435.13055

Sun Z, Liu Z, Zhou W et al (2016) Temporal interactions of plantinsect-predator after infection of bacterial pathogen on rice plants. Sci Rep 6:26043. https://doi.org/10.1038/srep26043

Tuomi J, Niemelä P, Chapin FS et al (1988) Defensive responses of trees in relation to their carbon/nutrient balance. Springer, New York, pp 57-72

Vänninen I, Tyni-Juslin J, Hokkanen H (2000) Persistence of augmented Metarhizium anisopliae and Beauveria bassiana in Finnishagricultural soils. Biocontrol 45(2):201-222

Vega F (2008) Insect pathology and fungal endophytes. J Invertebr Pathol 98(3):277-279. https://doi.org/10.1016/j.jip.2008.01.008 
Vega F (2018) The use of fungal entomopathogens as endophytes in biological control: a review. Mycologia 110(1):4-30. https://doi. org/10.1080/00275514.2017.1418578

Wagner BL, Lewis LC (2000) Colonization of corn, Zea mays, by the entomopathogenic fungus Beauveria bassiana. Appl Environ Microbiol 66(8):3468-3473. https://doi.org/10.1128/ AEM.66.8.3468-3473.2000

Wang S, Li XM, Liu CL et al (2013) The effects of different carbon or nitrogen sources on mycelial growth and sporulation of Beauveria bassiana. Heilongjiang Agric Sci 8:47-50

Weisany W, Sohrabi Y, Heidari G et al (2014) Effects of zinc application on growth, absorption and distribution of mineral nutrients under salinity stress in soybean (Glycine $\max$ L.). J Plant Nutr 37(14):2255-2269. https://doi.org/10.1080/01904167.2014.920386
Xiaoping Y, Yuchen H, Weidi L et al (2017) A study on the role of salicylic acid signaling pathways in mediating whitefly-induced indirect plant defense. J China Univ Metrol 28(1):1-6. https://doi. org/10.3969/j.issn.2096-2835.2017.01.001

Ye M, Song Y, Long J et al (2013) Priming of jasmonate-mediated antiherbivore defense responses in rice by silicon. Proc Natl Acad Sci 110(38):E3631-E3639. https://doi.org/10.1073/pnas.1305848110

Zhang Y, Zhao J, Fang W et al (2009) Mitogen-activated protein kinase hog1 in the entomopathogenic fungus Beauveria bassiana regulates environmental stress responses and virulence to insects. Appl Environ Microbiol 75(11):3787-3795. https://doi.org/10.1128/ AEM.01913-08

Publisher's Note Springer Nature remains neutral with regard to jurisdictional claims in published maps and institutional affiliations. 